
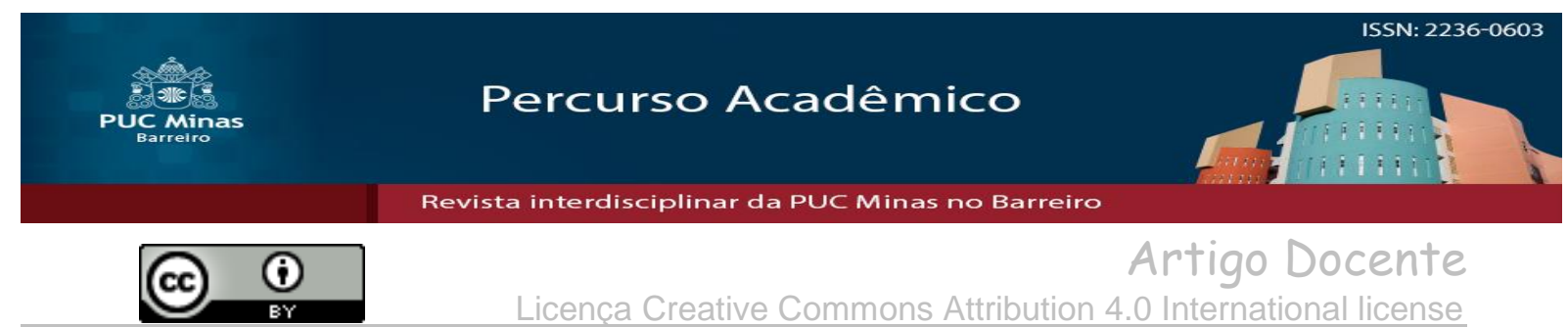

\title{
Programa de Aquisição de Alimentos (PAA-LEITE) e seus beneficiários: uma análise multivariada
}

\section{Food Acquisition Program (PAA-Milk) and its beneficiaries: a multivariate analysis}

\author{
Harine Matos Maciel ${ }^{1}$ \\ Ahmad Saeed Khan ${ }^{2}$
}

\begin{abstract}
Resumo
O objetivo deste artigo foi caracterizar e agrupar os beneficiários quanto às características estudadas (estados/municípios, sexo, categoria, grupo PRONAF - Programa Nacional de Fortalecimento da Agricultura Familiar e recursos repassados pelo Governo Federal) para identificar quais são mais relevantes no contexto do Programa de Aquisição de Alimentos (PAA-Leite). Os dados utilizados foram de origem secundária obtidos no site PAA - Data (SAGI-Secretaria de Avaliação e Gestão da Informação) do Ministério do Desenvolvimento Social (MDS), no ano de 2015. A metodologia utilizada foi a análise de agrupamento através do procedimento TwoStep Cluster. Os Estados com o maior número de municípios beneficiários são Minas Gerais e Pernambuco. O sexo masculino e os agricultores familiares são predominantes. A análise de agrupamento permitiu que os dados disponíveis dos beneficiários do PAA-Leite fossem agrupados em 5 clusters com base nas características disponíveis desta população (municípios/estados, sexo, categoria, Grupo PRONAF e os Recursos Financeiros (R\$) repassados pelo Governo Federal). Através da inferência estatística da significância das variáveis em cada grupo, chegou-se a conclusão de que todas as variáveis qualitativas analisadas (município, categoria, sexo e grupo PRONAF) foram significantes estatisticamente. Em geral, as variáveis mais significantes foram Município e Grupo PRONAF.
\end{abstract}

Palavras-chave: Pobreza. Leite. PRONAF.

\begin{abstract}
The aim of this paper was to characterize and group beneficiaries for the studied traits (states / counties, gender, category, PRONAF group and funds transferred by the federal government) to identify which are most relevant in the context of the Food Acquisition Program (PAA-Milk). The data used were of secondary origin obtained in PAA site - Date (SAGI-Secretariat for Evaluation and Information Management) in the Ministry of Social Development (MDS) in the year 2015. The methodology used was cluster analysis through the Two Step Procedure cluster. The states with the largest number of beneficiaries are municipalities Minas Gerais and Pernambuco. Beneficiaries of the PAA-Milk males and family farmers are prevalent. Cluster analysis allowed the available data of the PAA-Milk beneficiaries were grouped into five clusters based on the features available in this population (municipalities / states, sex, category, PRONAF Group and Financial Resources (R \$) transferred by the Federal Government). Through statistical inference of the significance of the variables in each group reached the conclusion that all qualitative variables (municipality, category, gender and PRONAF group) were statistically significant. In general, the most significant variables were Municipality and PRONAF Group.
\end{abstract}

Keywords: Poverty. Milk. PRONAF.

Artigo recebido em 17 de Março de 2016 e aprovado em 09 de Maio de 2017.

1 Doutoranda em Desenvolvimento e Meio Ambiente na Universidade Federal do Ceara (UFC). Professora do Instituto de Educação do Ceara (IFCE). E-mail harinematos@yahoo.com.br.

2 Doutor em Economia Rural, Programa de Pós-graduação em Desenvolvimento e Meio Ambiente e Economia Rural, Universidade Federal do Ceará (UFC), Fortaleza, Ceara, Brasil. E-mail: saeed@ufc.br. 


\section{Introdução}

A exclusão social está presente na sociedade brasileira desde os primórdios, tornando-se um preocupante obstáculo para o desenvolvimento nacional, visto que a exclusão trata dos desfavorecidos, da privação de recursos materiais e imateriais, da discriminação e da pobreza. Uma das formas de exclusão social mais presentes no Brasil é a pobreza, cuja característica principal é a carência de necessidades básicas, como alimentação, moradia, condições sanitárias, vestuário e de renda.

As políticas iniciais para o enfrentamento da pobreza foram pautadas no assistencialismo, que no curto prazo amenizaram a situação de vulnerabilidade social, mas a médio e longo prazo os manteve como a parcela dos menos desfavorecidos. Há muitas décadas, diversas políticas públicas que transferem renda com objetivo assistencial foram criadas no Brasil, como exemplo mais relevante cita-se o Programa Bolsa Família.

De acordo com o Governo Federal, a pobreza no Brasil está ligada a falta de recursos financeiros, a população carente não têm como se sustentar. Com isso foi criado, o Programa Fome Zero (PFZ), no ano de 2003, e se diferenciava dos outros programas propostos até então, pois se comprometia a solucionar em definitivo o problema da fome no Brasil.

O PFZ busca garantir o direito humano à alimentação adequada, promovendo a segurança alimentar e nutricional. Conforme o Projeto Fome Zero (2002) apud Yasbek (2004), a definição de segurança alimentar é a garantia do direito de todos ao acesso a alimentos de qualidade, em quantidade suficiente e de modo permanente, com base em práticas alimentares saudáveis e sem comprometer o acesso a outras necessidades essenciais e nem o sistema alimentar futuro, devendo se realizar em bases sustentáveis.

O PFZ é composto por um conjunto de programas que se complementam na busca pela erradicação da pobreza no país, além do auxílio financeiro por meiodo Bolsa Família e do microcrédito; o programa conta com construção de cisternas, restaurantes populares, orientação sobre hábitos alimentares e propostas para áreas rurais (Programa de Aquisição de Alimentos - PAA), principalmente, nas atividades ligadas à agropecuária e à agroindústria.

O PAA foi criado para facilitar a aquisição de produtos agropecuários produzidos por agricultores familiares que se enquadrem no Programa Nacional de 
Fortalecimento da Agricultura Familiar (PRONAF), dispensando o processo de licitação para a aquisição, desde que os preços não sejam superiores aos praticados nos mercados regionais.

Este Programa estabelece uma relação significativa entre os beneficiários dos programas sociais e os agricultores familiares, sendo estes, os principais responsáveis pelo fornecimento de gêneros alimentícios, contribuindo assim para a geração de emprego e renda no setor rural. Além de fortalecer a agricultura familiar, o outro objetivo é do combater a fome e a desnutrição, atendendo crianças de 2 a 7 anos, gestantes e idosos acima de 60 anos em situação de insegurança alimentar e nutricional, pertencentes a famílias com renda per capita de até meio salário mínimo, por meio da distribuição de merenda escolar em hospitais e entidades beneficentes.

O Programa Leite Fome Zero (PAA-Leite), foco desta pesquisa, é uma modalidade do PAA, e visa fortalecer a cadeia produtiva do leite. A integração entre os governos, federal, estadual e municipal são essenciais para que o programa atinja seus objetivos, já que são os governos locais que compram o leite dos produtores e distribuem aos beneficiários.

O PAA-Leite foi criado pela importância do produto, tanto no âmbito econômico, social e nutricional. Segundo o Instituto Brasileiro de Geografia e Estatística - IBGE (2006), a produção anual média de leite por estabelecimento agrícola obteve um aumento de $62 \%$, e a produção nacional de leite passou de 17,93 bilhões de litros em 1996 para 21,43 bilhões de litros no último censo agropecuário.

Tendo em vista os fatos apresentados e a relevância do PAA - Leite, o objetivo deste artigo foi caracterizar e agrupar os beneficiários quanto às características estudadas para identificar quais são as mais relevantes no contexto do Programa.

\section{A importância do leite e o Programa de Aquisição de Alimentos (PAA - Leite)}

O leite é uma importante fonte de proteínas e cálcio, sendo essencial para a saúde e para a alimentação de crianças, jovens, adultos e idosos, contribuindo para o desenvolvimento físico e intelectual. Atua melhorando o sistema imunológico e o fortalecimento de dentes e ossos.

Além da importância nutricional, a pecuária leiteira é relevante para o setor agropecuário brasileiro, uma vez que é produzido em todas as regiões brasileiras. A atividade leiteira no Brasil é constituída, principalmente, por uma grande parcela de pequenos produtores, mais de $50 \%$ da produção de leite nacional é gerada por 
agricultores familiares das regiões sul e norte. Milhares de famílias dependem da produção de leite e, por isso, é necessário um fortalecimento da cadeia produtiva por meio de políticas públicas de longo prazo que viabilizassem melhores condições de assistência técnica, capacitação, facilitação de crédito, incentivo ao associativismo para combater a informalidade do setor que ainda é muito grande -, infraestrutura adequada, adoção de novas tecnologias, estabelecimento de um padrão de qualidade para o produto, entre outros. (OLIVIERA; KHAN; LIMA, 2015).

Um melhor conhecimento da atividade leiteira é de fundamental importância para o desenvolvimento de políticas públicas que atuem para o melhoramento do setor. Desta forma, o governo brasileiro cria no ano de 2003 o PAA que consiste em uma política pública voltada para a agricultura familiar, contemplando os municípios que apresentassem uma parcela significativa da população em condição de insegurança alimentar. Um dos objetivos é fortalecer setores produtivos, no caso do Leite, incentivando a produção local, com geração de emprego e renda. E esta política, além de incentivar a produção, também auxilia pessoas que estão em situação insegurança alimentar.

O PAA-leite é uma das linhas mais importantes do Programa de Aquisição de Alimentos, e segundo DESER (2008) incentiva o consumo e a produção familiar deste produto, visando à diminuição da vulnerabilidade social, pelo combate à fome e à desnutrição; além de contribuir para o fortalecimento do setor produtivo familiar, pela aquisição e distribuição de leite com garantia de preço.

\section{Metodologia}

A área geográfica de estudo compreendeu o território da Superintendência do Desenvolvimento do Nordeste (SUDENE) onde é executado o PAA-Leite, sendo beneficiados todos os estados da região Nordeste e também o norte do Estado de Minas Gerais.

Os dados utilizados foram de origem secundária obtidos no site PAA - Data (SAGI - Secretaria de Avaliação e Gestão da Informação) do Ministério do Desenvolvimento Social (MDS) no ano de 2015.

O objetivo do estudo é o agrupamento dos beneficiários do PAA-Leite, segundo características comuns (estados/municípios, sexo, categoria, grupo PRONAF e recursos repassados pelo Governo Federal) disponíveis no site do programa. A metodologia utilizada foi o agrupamento através do procedimento TwoStep Cluster. 
O método TwoStep mostra agrupamentos naturais dentro de uma série de dados que de outra maneira não se mostra aparente. De acordo com Schiopu (2010), as vantagens de se utilizar este método são a possibilidade da utilização de variáveis contínuas e categóricas e o cálculo automático do número ideal de clusters.

Os agrupamentos ou clusters foram formados com a base de dados que abrangeu os beneficiários pelo PAA-Leite no ano de 2014, segundo o site PAA data, coletados no mês de novembro de 2015. Após a obtenção dos dados, estes foram organizados no programa estatístico SPSS 20.0 que gerou o output do método de agrupamento TwoStep Cluster. Foi utilizado o procedimento de obtenção automática dos clusters pelo método Critério de Informação Bayesiano (BIC) e este indicou a formação de 5clusters ou agrupamentos. A qualidade do agrupamento indicou uma solução justa, valores compreendidos entre 0,2 e 0,5 .

Após o método TwoStep Cluster agrupar os dados da população estudada, foi realizada a análise de segmentação cujo objetivo principal foi definir a estrutura desses dados, alocando os casos mais similares no mesmo grupo, baseado nas características em que foram medidos. Quando o agrupamento dos dados é bem sucedido, os indivíduos pertencentes ao mesmo grupo são mais semelhantes entre si, tornando os grupos homogêneos internamente e heterogêneos externamente.

\section{Resultados e discussão}

Neste ponto apresentam-se as características sociais, econômicas e os resultados relativos à Análise de Agrupamento dos beneficiários pelo PAA-Leite nos Estados da região Nordeste e do norte do Estado de Minas Gerais no ano de 2015.

\subsection{Características Socioeconômicas}

\section{a) Estados e Municípios}

O Programa de Aquisição de Alimentos (PAA-Leite) tem como um dos objetivos principais estimular a produção de leite bovino e caprino dos agricultores familiares visando o fortalecimento deste setor e, consequentemente, da agricultura familiar. Os beneficiários do PAA-Leite até o ano de 2015 estavam na região Nordeste e no norte do Estado de Minas Gerais, ou seja, no território da Superintendência do Desenvolvimento do Nordeste (SUDENE), não havendo previsão de ser expandido para outras regiões do Brasil. Somente o Estado do Piauí na região Nordeste, no ano em 
estudo, não constava nenhum beneficiário, devido a problemas de operacionalização do programa no Estado.

Com base na tabela 1, os Estados com o maior número de municípios beneficiários são Minas Gerais (104), Pernambuco (72), Rio Grande do Norte (67) e Bahia (66); e o menor número de municípios encontra-se em Sergipe (04) e no Maranhão (07). O que explica esses números é que a produção de leite é muito significativa, principalmente no Estado de Minas Gerais que é o maior produtor no Brasil, seguido por Estados da Região Sul, Goiás, São Paulo; na Região Nordeste os maiores produtores são Bahia e Pernambuco.

Conforme os dados da Pesquisa Pecuária Municipal, desenvolvida pelo IBGE, no ano de 2014, a produção de leite foi de 35,17 bilhões de litros, representando um aumento de 2,7\% em relação à registrada no ano anterior. As regiões Norte e Nordeste lideraram o crescimento na produção de leite no Brasil. As regiões Sul e Sudeste correspondem a 69,3\% da produção brasileira de leite, em seguida a região centro-oeste com $14,1 \%$ e depois a região nordeste com $11,1 \%$, mostrando um crescimento contínuo neste setor, apesar das graves estiagens e secas dos últimos anos.

Tabela 1: Distribuição absoluta e relativa dos beneficiários do PAA-Leite nos Estados da Região Nordeste e do norte do Estado de Minas Gerais - 2015

\begin{tabular}{lccc}
\hline \multicolumn{1}{c}{ Estados } & $\begin{array}{c}\text { Quantidade de } \\
\text { Municípios }\end{array}$ & $\begin{array}{c}\text { Quantidade de } \\
\text { Beneficiários } \\
\text { (Frequência Absoluta) }\end{array}$ & $\begin{array}{c}\text { Quantidade de Beneficiários } \\
\text { (Frequência Relativa \%) }\end{array}$ \\
\hline Alagoas & 65 & 3.877 & 19,34 \\
Bahia & 66 & 1.259 & 6,28 \\
Ceará & 47 & 1.573 & 7,84 \\
Maranhão & 07 & 372 & 1,85 \\
Minas Gerais & 104 & 4.576 & 22,82 \\
Paraíba & 55 & 2.014 & 10,04 \\
Pernambuco & 72 & 5.244 & 26,16 \\
Rio Grande do Norte & 67 & 1.135 & 5,65 \\
Sergipe & 04 & 04 & 0,02 \\
\hline Total & $\mathbf{4 8 7}$ & $\mathbf{2 0 . 0 5 4}$ & $\mathbf{1 0 0 , 0 0}$ \\
\hline
\end{tabular}

Fonte: SAGI - PAA - Data.

Quando se analisa a quantidade de beneficiários por Estados, o maior número se encontra em Pernambuco (26,16\%), Minas Gerais (22,82\%) e Alagoas (19,34\%). O Estado de Pernambuco criou o "Programa Leite para Todos", em Minas Gerais foi criado o "Projeto Leite Fome Zero - Um Leite pela Vida" e em Alagoas criou-se o "Mais Leite", todos foram criados com o intuito de auxiliar no crescimento e desenvolvimento do PAA-leite nas regiões beneficiadas, contribuindo assim para o sucesso deste Programa nas regiões contempladas. 
A menor quantidade de beneficiários acompanha o resultado do menor número de municípios, sendo estes os estados de Sergipe (0,02\%) e Maranhão (1,85\%). Ambos estão em constante crescimento na produção de leite nos últimos anos, mas quando comparados com os outros Estados beneficiários ainda há muito a ser desenvolvido. Grande parte da produção leiteira é composta por pequenos produtores e existem diversas ações governamentais, como o PAA-Leite, para desenvolver a cadeia produtiva do leite nesses estados. O Estado de Sergipe, de acordo com o Serviço Brasileiro de Apoio as Micro e Pequenas Empresas - SEBRAE (2014), alcançou, em termos percentuais, o maior crescimento de produção de leite na região Nordeste, confirmando assim o desenvolvimento destas regiões.

O Estado do Rio Grande do Norte possui a terceira maior quantidade de municípios beneficiários, porém o número de beneficiários não acompanhou este ranking, ocupando o sexto lugar, mostrando que há beneficiários distribuídos por vários municípios, mas não há uma concentração deles, isso é bom por um lado porque o Estado está beneficiando pessoas de regiões diferentes do estado, mas também dificulta a criação de associações e cooperativas para a produção no setor, buscando com isso melhorar continuamente a cadeia produtiva.

\section{b) Sexo}

Os beneficiários do Programa de Aquisição de Alimentos (PAA-Leite), 80,11\% são do sexo masculino enquanto $19,89 \%$ são do sexo feminino. Nas regiões beneficiárias a produção leiteira, em sua maioria, é tratada como uma atividade masculina devido à necessidade de força física, lida com os animais e, principalmente, a ordenha.

Muitas pesquisas garantem que a divisão dos sexos na atividade leiteira se deve a cultura de diversas localidades. Paulilo et al. (2003) afirma que na atividade leiteira a predominância, antigamente, na região Sul, era feminina, mas com a modernização do processo produtivo a mulher perdeu espaço para o sexo masculino, desempenhando uma função submissa; tornando assim o meio rural mais masculino.

Em todos os Estados beneficiários, o sexo masculino foi predominante, acima de $70 \%$, como mostra a tabela 2. O Estado com a maior presença masculina foi a Paraíba $(86,5 \%)$ e o menor a Bahia (73,2\%). Esperava-se que o Estado de Minas Gerais obtivesse a maior porcentagem feminina, já que as atividades agropecuárias 
desenvolvidas na Região Nordeste são culturalmente realizadas, em grande parte, pelos homens; mostrando assim que a tradição e a cultura podem ser superadas pelo empenho, trabalho, compromisso e coragem por parte das mulheres em reivindicar seus lugares no seio familiar, não só como mãe e esposa, e sim como uma trabalhadora em qualquer ramo de atividade.

Tabela 2: Distribuição absoluta e relativa por gênero dos beneficiários do PAALeite na Região Nordeste e do norte do Estado de Minas Gerais - 2015

\begin{tabular}{lcccc}
\hline \multirow{2}{*}{ Gênero/Estados } & \multicolumn{2}{c}{ Masculino } & \multicolumn{2}{c}{ Feminino } \\
\cline { 2 - 5 } & $\begin{array}{c}\text { Frequência } \\
\text { Absoluta }\end{array}$ & $\begin{array}{c}\text { Frequência } \\
\text { Relativa (\%) }\end{array}$ & $\begin{array}{c}\text { Frequência } \\
\text { Absoluta }\end{array}$ & $\begin{array}{c}\text { Frequência } \\
\text { Relativa (\%) }\end{array}$ \\
\hline Alagoas & 3.108 & 80,2 & 769 & 19,8 \\
Bahia & 922 & 73,2 & 337 & 26,8 \\
Ceará & 1.208 & 76,8 & 365 & 23,2 \\
Maranhão & 312 & 83,9 & 60 & 16,1 \\
Minas Gerais & 3.906 & 85,4 & 670 & 14,6 \\
Paraíba & 1.743 & 86,5 & 271 & 13,5 \\
Pernambuco & 3.974 & 75,8 & 1.270 & 24,2 \\
Rio Grande do Norte & 891 & 78,5 & 244 & 21,5 \\
Sergipe & 03 & 75,00 & 01 & 25,00 \\
\hline Total & $\mathbf{1 6 . 0 6 7}$ & $\mathbf{8 0 , 1 1}$ & $\mathbf{3 . 9 8 7}$ & $\mathbf{1 9 , 8 9}$ \\
\hline
\end{tabular}

Fonte: SAGI - PAA - Data.

Mesmo com o crescente aumento das mulheres no mercado de trabalho, na agricultura familiar ainda é a figura do homem tratada como chefe. Segundo Melo (2002), o sexo masculino foi eleito secularmente como o responsável pelo exercício das atividades desenvolvidas "fora do espaço da casa".

\section{c) Grupo PRONAF}

A agricultura familiar é responsável por diversos produtos consumidos pela população brasileira como milho, arroz, feijão, leite, mandioca, entre outros. De acordo com o Banco do Nordeste do Brasil - BNB (2012), a agricultura familiar é responsável por $82,9 \%$ da ocupação de mão de obra no campo. Com o objetivo de fortalecer esse setor tão essencial pra a economia brasileira e manter o produtor na área rural, de concessões de crédito para investimento e custeio das atividades agropecuárias e não agropecuárias, o governo federal criou o Programa Nacional de Fortalecimento da Agricultura Familiar (PRONAF), no ano de 1995.

Com mais de 2,6 milhões de famílias beneficiadas, o Programa de Fortalecimento da Agricultura Familiar (PRONAF) transformou a vida dos brasileiros residentes no campo e, atualmente, é exemplo mundial de política pública de sucesso. Nesses anos de existência, 5.379 munícipios foram contemplados com cerca de R \$ 156 
bilhões em projetos, cujo financiamento partiu de contratos assinados no âmbito do PRONAF. (PORTAL BRASIL, 2015, p.1).

Um dos requisitos para ser beneficiário do Programa de Aquisição de Alimentos (PAA-Leite) é também ser beneficiário do Programa Nacional de Fortalecimento da Agricultura Familiar (PRONAF). Vieira; Viana (2001) afirmam que o PAA é um mecanismo complementar ao PRONAF ao apoiar a comercialização dos produtos alimentícios dos estabelecimentos de produção familiar.

Um dos aspectos inovadores do Programa de Aquisição de Alimentos (PAA) é que consiste em um instrumento de política pública que integra, não apenas em sua concepção, mas também nos aspectos práticos de sua operacionalização, dimensões relacionadas tanto à política agrícola como à política de segurança alimentar e nutricional. (SCHMITT, 2005, p.78).

Na tabela 3 nota-se que $45 \%$ dos beneficiários do PAA-Leite são beneficiários da modalidade $\mathrm{V}$ ou AF do PRONAF, na qual se destina a investimentos para atividades agropecuárias e para os agricultores familiares que não se enquadram no grupo A, B e A/C. O PRONAF B, destinado a investimento ou custeio, possui 38,92\% dos beneficiários totais do PAA-Leite. A menor participação é do PRONAF A/C, 0,93\%, destinada ao custeio das atividades agropecuárias e não agropecuárias.

Tabela 3: Distribuição absoluta e relativa segundo o Grupo do PRONAF dos beneficiários nos Estados da Região Nordeste e do norte do Estado de Minas Gerais - 2015

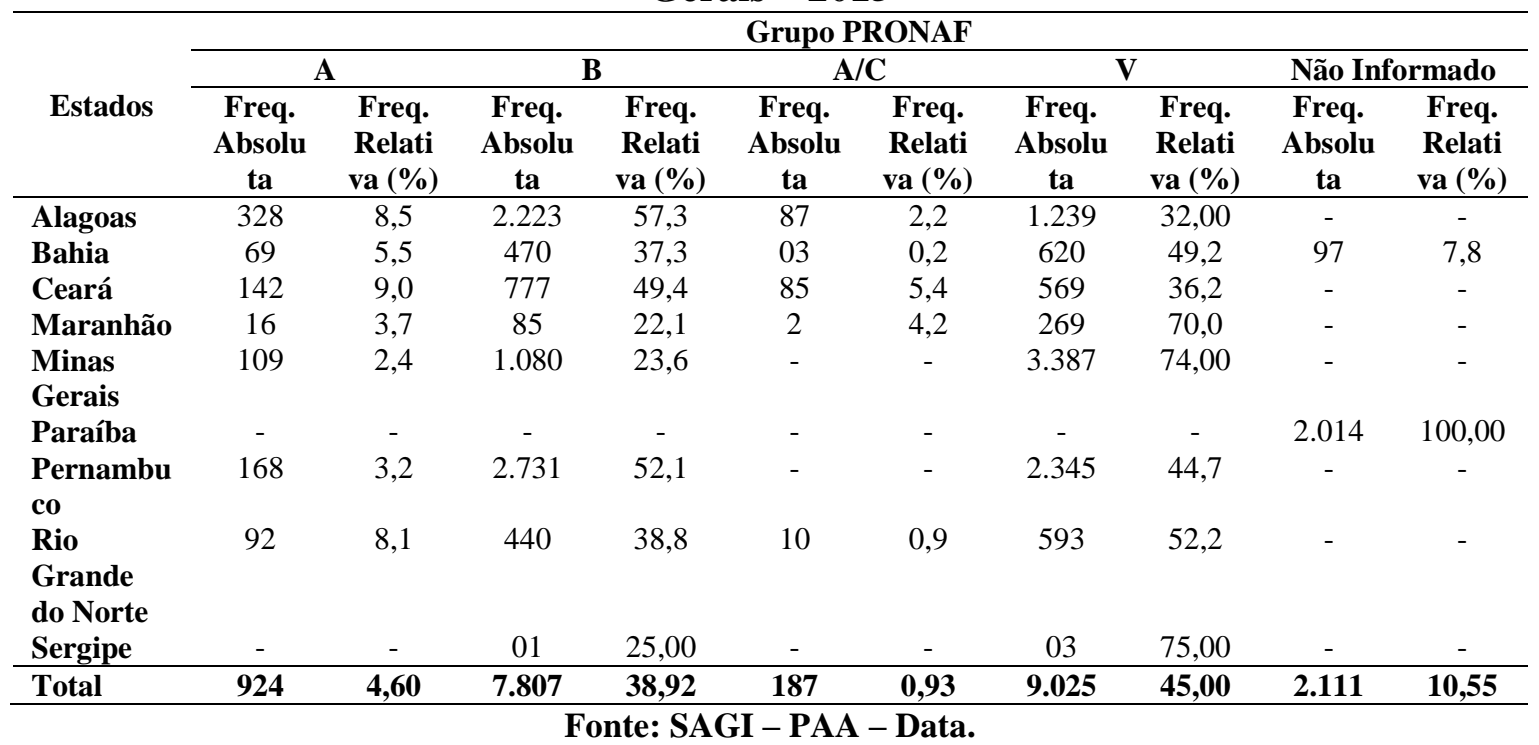


O Estado da Paraíba foi o único estado em que $100 \%$ dos beneficiários não continham a informação acerca do tipo de PRONAF ao qual estão vinculados. Dos nove estados contemplados pelo PAA-Leite, seis possuem a maior parte dos beneficiários do PRONAF V ou AF. Este grupo PRONAF abrange o maior intervalo da renda bruta familiar permitido pelo Programa, acima de $\mathrm{R} \$ 10.000,00$ e no limite de $\mathrm{R} \$ 160.000,00$, nos últimos 12 meses, e nestes valores precisam estar incluídos a renda de todas as atividades desenvolvidas dentro e fora do estabelecimento rural por todos os membros da família.

\section{d) Categoria}

As categorias contempladas pelo PAA-Leite são seis: agricultor familiar, agroextrativista, assentado da reforma agrária, trabalhador rural sem terra, quilombola e pescador. Os agricultores familiares constituem 85,98\% dos beneficiários do Programa e 11,26\% não informaram a categoria a qual pertence. Os pescadores são a categoria com a menor porcentagem, $0,0049 \%$ (tabela 4 ). 
Tabela 4: Distribuição absoluta e relativa (\%) segundo as Categorias dos beneficiários nos Estados da Região Nordeste e do norte do Estado de Minas Gerais - 2015

\begin{tabular}{|c|c|c|c|c|c|c|c|c|c|c|c|c|c|c|}
\hline Estados & \multicolumn{2}{|c|}{$\begin{array}{l}\text { Agricultor } \\
\text { Familiar }\end{array}$} & \multicolumn{2}{|c|}{ Agroextrativista } & \multicolumn{2}{|c|}{$\begin{array}{c}\text { Assentado da Reforma } \\
\text { Agrária }\end{array}$} & \multicolumn{2}{|c|}{$\begin{array}{c}\text { Categorias } \\
\text { Trabalhador Rural } \\
\text { Sem Terra }\end{array}$} & \multicolumn{2}{|c|}{ Quilombola } & \multicolumn{2}{|c|}{ Pescador } & \multicolumn{2}{|c|}{ Não Informado } \\
\hline $\mathbf{A L}$ & 3.877 & 100 & - & - & - & - & - & - & - & - & - & - & - & - \\
\hline CE & - & - & - & - & - & - & - & - & - & - & - & - & 1.573 & 100 \\
\hline MA & 371 & 99,7 & - & - & - & - & - & - & - & - & - & - & 01 & 0,3 \\
\hline MG & 3.439 & 75,3 & 373 & 8,2 & 70 & 1,4 & 02 & 0,04 & 05 & 0,1 & 01 & 0,02 & 686 & 15 \\
\hline PB & 2.014 & 100 & - & - & - & - & - & - & - & - & & - & - & - \\
\hline SE & 04 & 100 & - & - & - & - & - & - & - & - & - & - & - & - \\
\hline Total & 17.241 & - & 373 & - & 172 & - & 02 & - & 05 & - & 01 & - & 2.260 & - \\
\hline
\end{tabular}


O Estado de Pernambuco possui o maior número de beneficiários agricultores familiares, 5.244 beneficiários. Os Estados da Paraíba, Alagoas e Bahia detém 100\% dos beneficiários na categoria de agricultura familiar. Já no Estado do Ceará, 100\% não informaram a qual categoria pertencem.

Minas Gerais é o único Estado que possui beneficiários em todas as categorias, sendo que $75,3 \%$ são agricultores familiares, $15 \%$ não informaram e $8,2 \%$ são agroextrativistas. O menor número de beneficiários é composto por pescadores, $0,02 \%$ do total de beneficiários.

\section{e) Recursos (R\$)}

O orçamento do PAA é composto por recursos do Ministério do Desenvolvimento Social e Combate à Fome (MDS) e do Ministério do Desenvolvimento Agrário (MDA). Os recursos repassados pelo Governo Federal, por meio de Termos de Cooperação através da Companhia Nacional de Abastecimento (CONAB), responsável pela operacionalização, para os Estados beneficiários pelo PAA-Leite, até o ano de 2014, somavam R\$ 117.358.969,42, sendo o Estado de Alagoas o que mais recebeu recursos (27,20\%); em segundo lugar encontra-se Minas Gerais $(25,10 \%)$. O Estado de Sergipe é o que possui os recursos mais baixos $(0,04 \%)$ do total repassado seguido de Maranhão (0,98\%), já que estes Estados possuem as menores quantidades de beneficiários, sendo 04 em Sergipe e 372 no Maranhão, como mostra a tabela 5 .

Tabela 5: Distribuição absoluta e relativa segundo os Recursos Repassados pelo Governo Federal dos beneficiários nos Estados da Região Nordeste e do norte do Estado de Minas Gerais - 2015

\begin{tabular}{lcc}
\hline \multicolumn{2}{c}{ Estados } & \multicolumn{2}{c}{ Recursos Repassados pelo Governo Federal } \\
\hline & Frequência Absoluta & Frequência Relativa (\%) \\
Alagoas & $31.930 .899,33$ & 27,20 \\
Bahia & $9.829 .826,27$ & 8,37 \\
Ceará & $13.221 .004,08$ & 11,26 \\
Maranhão & $1.152 .601,00$ & 0,98 \\
Minas Gerais & $29.459 .276,36$ & 25,10 \\
Paraíba & $10.729 .800,17$ & 9,14 \\
Pernambuco & $16.621 .297,34$ & 14,16 \\
Rio Grande do Norte & $4.405 .460,65$ & 3,75 \\
Sergipe & $8.804,22$ & 0,04 \\
\hline Total & $\mathbf{1 1 7 . 3 5 8 . 9 6 9 , 4 2}$ & $\mathbf{1 0 0 , 0 0}$ \\
\hline \multicolumn{2}{c}{ Fonte: SAGI - PAA - Data. }
\end{tabular}




\subsection{Perfil dos agrupamentos}

A análise de agrupamento permitiu que os dados disponíveis dos beneficiários do PAA-Leite fossem agrupados em clusters, de modo que os elementos pertencentes a cada cluster apresentassem grande similaridade entre eles. Estes cinco grupos resultam da análise de cinco variáveis que tinham o objetivo de caracterizar e agrupar os beneficiários do PAA-Leite. As variáveis utilizadas para a análise foram os municípios/estados, sexo, categoria, Grupo PRONAF e os Recursos Financeiros (R\$) repassados pelo Governo Federal.

A tabela 6 mostra os clusters gerados. Observa-se que 100\% dos beneficiários da base de dados foram combinados em algum cluster, ou seja, nenhum caso precisou ser excluído. Foi possível classificar em grupos homogêneos a totalidade dos beneficiários, separados em cinco grupos, nos quais os grupos $4(33,5 \%)$ e $2(26,5 \%)$ possuem a maior quantidade de beneficiários, enquanto que a menor quantidade ficou com o grupo 5 $(10,5 \%)$. A porcentagem de objetos combinados maior ficou no grupo 4, mostrando que 33,5\% dos beneficiários pelo Programa de Aquisição de Alimentos (PAA-Leite) possuem características semelhantes referentes as variáveis utilizadas nesta pesquisa.

Tabela 6: Distribuição dos Clusters

\begin{tabular}{cccc}
\hline $\begin{array}{c}\text { Clusters } \\
\text { Formados }\end{array}$ & $\begin{array}{c}\text { Tamanho dos Clusters } \\
\text { (número de } \\
\text { beneficiários) }\end{array}$ & $\begin{array}{c}\text { \% de objetos } \\
\text { combinados }\end{array}$ & \% do total \\
\hline $\mathbf{1}$ & 2.807 & 14,0 & 14,0 \\
$\mathbf{2}$ & 5.324 & 26,5 & 26,5 \\
$\mathbf{3}$ & 3.095 & 15,4 & 15,4 \\
$\mathbf{4}$ & 6.717 & 33,5 & 33,5 \\
$\mathbf{5}$ & 2.111 & 10,5 & 10,5 \\
Combinados & 20.054 & 100,0 & 100,0 \\
Casos Excluídos & 0 & & 0 \\
\hline Total & $\mathbf{2 0 . 0 5 4}$ & $\mathbf{1 0 0 , 0}$ \\
\hline
\end{tabular}

Fonte: Resultados da Pesquisa.

Ao analisar os clusters separadamente, nota-se que os perfis dos beneficiários modificam um pouco entre os grupos. A tabela 7 mostra a distribuição dos grupos segundo o gênero, no qual $80,11 \%$ do total são compostos pelo sexo masculino, apesar da prioridade dada as mulheres nos principais programas sociais do Governo Federal como Bolsa Família, Minha Casa Minha Vida e Reforma Agrária. No entanto, quando se trata de atividades agropecuárias o sexo masculino ainda predomina.

Os grupos 2 e 4 possuem 100\% do sexo masculino, são os grupos com o maior numero de beneficiários, comprovando a maioria masculina. Os grupos 1 e 5 contém a maioria masculina, acima de $75 \%$. Já no grupo 3 , diferentemente dos outros grupos 
formados, foram agrupados $100 \%$ do sexo feminino, confirmando a homogeneidade dentro dos grupos formados pela técnica utilizada de análise multivariada.

Tabela 7: Distribuição dos Clusters segundo o Gênero

\begin{tabular}{ccccc}
\hline \multirow{2}{*}{ Cluster } & \multicolumn{3}{c}{ Feminino } & \multicolumn{2}{c}{ Masculino } \\
& Freq. Absoluta & Freq. Relativa (\%) & Freq. Absoluta & Freq. Relativa (\%) \\
\hline $\mathbf{1}$ & 596 & 21,24 & 2.211 & 78,76 \\
$\mathbf{2}$ & 0 & 0,0 & 5.324 & 100,0 \\
$\mathbf{3}$ & 3.095 & 100,0 & 0 & 0,0 \\
$\mathbf{4}$ & 0 & 0,0 & 6.717 & 100,0 \\
$\mathbf{5}$ & 296 & 14,03 & 1.815 & 85,97 \\
\hline Total & $\mathbf{3 . 9 8 7}$ & $\mathbf{1 0 0}$ & $\mathbf{1 6 . 0 6 7}$ & $\mathbf{1 0 0 , 0}$ \\
\hline
\end{tabular}

Fonte: Resultados da Pesquisa.

De acordo com os recursos disponibilizados pelo Governo Federal para o Programa de Aquisição de Alimentos (PAA-Leite), a média total dos grupos foi de R\$ 5.503.220,00, como mostra a tabela 8. Não houve grandes disparidades entre os clusters formados, já que os valores médios estão todos acima de $\mathrm{R} \$ 5.000 .000,00$.

Tabela 8: Distribuição dos Clusters segundo Recursos

\begin{tabular}{|c|c|c|}
\hline \multirow{2}{*}{ Cluster } & \multicolumn{2}{|c|}{ Recursos } \\
\hline & Média (R\$) & Desvio Padrão \\
\hline 1 & $5.480 .310,00$ & $2.406,06$ \\
\hline 2 & 5.741. 140,00 & $1.912,59$ \\
\hline 3 & $5.402 .020,00$ & $2.062,82$ \\
\hline 4 & $5.422 .040,00$ & $2.154,42$ \\
\hline 5 & $5.340 .290,00$ & $2.609,84$ \\
\hline Total & $5.503 .220,00$ & $2.174,97$ \\
\hline
\end{tabular}

Fonte: Resultados da Pesquisa.

Com base nas categorias dos beneficiários pelo programa, a maioria são compostos de agricultores familiares (tabela 9). Os grupos 4 e 5 são compostos por $100 \%$ de agricultores familiares. Já nos grupos 2 e 3 quase $100 \%$ são agricultores familiares e o pequeno percentual restante não informaram ou são assentados da reforma agrária, respectivamente. O grupo 1 é o mais heterogêneo, pois possui o maior número de categorias, $80,5 \%$ não informaram, $11,3 \%$ são extrativistas e $8,2 \%$ são assentados da reforma agrária, não havendo nenhum agricultor familiar.

Os dados não informados referem-se a algum tipo de erro na coleta e operacionalização, já que é uma informação essencial para participar do Programa. Há grande probabilidade que esses $80,5 \%$ que não informaram no grupo 1 sejam pertencentes da categoria de agricultores familiares, já que é a atividade que mais se beneficia pelo PAA-Leite. 
Tabela 9: Distribuição dos Clusters segundo a Categoria

\begin{tabular}{cccccc}
\hline \multirow{2}{*}{ Cluster } & \multicolumn{4}{c}{ Categoria em \% } & Total \\
\cline { 2 - 5 } & $\begin{array}{c}\text { Agricultor } \\
\text { Familiar }\end{array}$ & $\begin{array}{c}\text { Não } \\
\text { Informado }\end{array}$ & Agroextrativista & $\begin{array}{c}\text { Assentado da } \\
\text { Reforma Agrária }\end{array}$ & \\
\hline $\mathbf{1}$ & 0,0 & 80,5 & 11,3 & 8,2 & 100,0 \\
$\mathbf{2}$ & 99,9 & 0,1 & 0,0 & 0,0 & 100,0 \\
$\mathbf{3}$ & 99,9 & 0,0 & 0,0 & 0,1 & 100,0 \\
$\mathbf{4}$ & 100,0 & 0,0 & 0,0 & 0,0 & 100,0 \\
$\mathbf{5}$ & 100,0 & 0,0 & 0,0 & 0,0 & 100,0 \\
\hline
\end{tabular}

Fonte: Resultados da Pesquisa.

A forte presença dos agricultores familiares como a grande maioria, se deve ao fato de que para ser beneficiário do Programa de Aquisição de Alimentos (PAA-Leite) é necessário ser beneficiário de uma outra política pública que é o Programa Nacional de Fortalecimento da Agricultura Familiar (PRONAF), programa este que trouxe a discussão da verdadeira importância econômica e social da agricultura familiar.

A tabela 10 apresenta a distribuição dos clusters com base no grupo PRONAF. Não há o que se concluir do grupo 5, o menor grupo formado, já que $100 \%$ dos beneficiários não informaram a qual grupo PRONAF pertenciam. Os outros dois menores grupos que são os grupos 1 e 3 são os mais heterogêneos, possuindo todas as categorias estudadas. Em ambos os grupos o tipo de PRONAF predominante foi o B e o $\mathrm{V}$.

No maior grupo formado, cluster 4 , mais de $95 \%$ pertencem ao grupo $\mathrm{V}$ e o restante ao grupo A. E no segundo maior cluster formado a composição é bem diferente, sendo quase $90 \%$ do grupo B e os outros do PRONAF do tipo A e A/C.

Tabela 10: Distribuição dos Clusters segundo o Grupo PRONAF

\begin{tabular}{ccccccc}
\hline & \multicolumn{5}{c}{ Grupo PRONAF em \% } & \multirow{2}{*}{ Total } \\
\cline { 2 - 5 } Cluster & $\mathbf{A}$ & $\mathbf{B}$ & $\mathbf{A} / \mathbf{C}$ & $\mathbf{V}$ & $\begin{array}{c}\text { Não } \\
\text { Informado }\end{array}$ & \\
\hline $\mathbf{1}$ & 19,1 & 28,6 & 4,0 & 48,3 & 0,0 & 100,0 \\
$\mathbf{2}$ & 8,7 & 89,4 & 1,9 & 0,0 & 0,0 & 100,0 \\
$\mathbf{3}$ & 15,0 & 57,3 & 2,0 & 25,7 & 0,0 & 100,0 \\
$\mathbf{4}$ & 0,2 & 3,3 & 0,0 & 96,5 & 0,0 & 100,0 \\
$\mathbf{5}$ & 0,0 & 0,0 & 0,0 & 0,0 & 100,0 & 100,0 \\
\hline
\end{tabular}

Fonte: Resultados da Pesquisa.

A participação dos Estados foi retratada na tabela 11, os grupos com a maior participação dos estados são 3, 4 e 2, respectivamente. Porém nestes grupos não há a participação dos Estados do Ceará, Paraíba e Sergipe. O grupo 5 possui a menor participação em números de estados, são apenas Bahia e Paraíba. Os estados com menores participações nos clusters são o Ceará que está presente somente no cluster 1 
(no qual 56,03\% do cluster é composto por municípios cearenses), e a Paraíba no cluster 5 (95,40\% é composto por municípios paraibanos).

Tabela 11: Distribuição dos Clusters segundo os Estados

\begin{tabular}{cccccccccc}
\hline & \multicolumn{8}{c}{ Estados em \% } \\
\cline { 2 - 5 } & Alagoas & Bahia & Ceará & Maranhão & $\begin{array}{c}\text { Minas } \\
\text { Gerais }\end{array}$ & Paraíba & Pernambuco & $\begin{array}{c}\text { Rio } \\
\text { Grande } \\
\text { do } \\
\text { Norte }\end{array}$ & Sergipe \\
\hline $\mathbf{1}$ & 0,0 & 0,00 & 56,03 & 0,13 & 40,25 & 0,00 & 0,00 & 3,59 & 0,00 \\
$\mathbf{2}$ & 38,32 & 6,44 & 0,00 & 1,14 & 10,20 & 0,00 & 38,17 & 5,73 & 0,00 \\
$\mathbf{3}$ & 24,81 & 10,05 & 0,00 & 1,94 & 14,67 & 0,00 & 41,00 & 7,33 & 0,2 \\
$\mathbf{4}$ & 15,87 & 7,52 & 0,00 & 3,80 & 36,40 & 0,00 & 28,88 & 7,41 & 0,12 \\
$\mathbf{5}$ & 0,00 & 4,60 & 0,00 & 0,00 & 0,00 & 95,40 & 0,00 & 0,00 & 0,00 \\
\hline \multicolumn{8}{c}{ Fonte: Resultados da Pesquisa. }
\end{tabular}

O Estado do Piauí estava presente na lista dos beneficiários do PAA-Leite, mas por problemas de operacionalização do Programa, no ano em estudo, não houve nenhum beneficiário. Em situação similar encontra-se o Estado de Sergipe, que constava na lista apenas com 04 beneficiários.

Ao analisar a participação dos municípios nos clusters formados, no grupo $1 \mathrm{o}$ município com a maior participação é do Estado do Ceará, Banabuiú com 14,4\%. No grupo 2 com 5,2\% é o município pernambucano, Lagoa do Ouro. No 3 é também um município pernambucano chamado de Buíque $(4,8 \%)$. Já no grupo 4 é o município mineiro de Malacacheta com 6,7\% e, por fim, no grupo 5 o município paraibano de Monteiro com 15,5\%. Concluindo que os municípios de Pernambuco, Ceará, Minas Gerais e Paraíba são os que mais apareceram na formação dos clusters.

Após a análise de clusters, os dados foram submetidos a testes de significância estatística para avaliar quais as variáveis que tiveram importância na formação dos grupos. Através da inferência estatística da significância das variáveis em cada grupo, teste qui-quadrado, chegou-se a conclusão de que todas as variáveis qualitativas analisadas (município, categoria, sexo e grupo PRONAF) foram significantes estatisticamente. Ao analisar os clusters separadamente, as variáveis mais significantes em cada grupo foram: Cluster 1: Categoria e Município; Cluster 2: Grupo PRONAF e Município; Cluster 3: Sexo; Cluster 4 e 5: Grupo PRONAF e Município.

Em geral, as variáveis mais significantes foram Município e Grupo PRONAF, porém Município foi a mais significante nos grupos 1, 2, 4 e 5, enquanto o Grupo PRONAF foi na 2, 4 e 5. Já as variáveis menos significantes houve uma maior heterogeneidade entre os grupos, no cluster 1 e 5 foi a variável sexo, Grupo PRONAF no cluster 2, Categoria no cluster 3 e 4 . 
Com relação a variável quantitativa, recursos repassados pelo Governo Federal para o Programa de Aquisição de Alimentos (PAA-Leite), com base no teste t de student, concluiu-se que foi significante apenas no cluster 2 que obteve a maior média entre os grupos analisados, apesar de não ter ocorrido grandes disparidades entre os grupos referentes aos recursos repassados.

\section{Considerações finais}

O objetivo deste artigo foi caracterizar e agrupar os beneficiários quanto às características estudadas para identificar quais são mais relevantes no contexto do Programa de Aquisição de Alimentos (PAA-Leite).

Os Estados com o maior número de municípios beneficiários são Minas Gerais e Pernambuco. O sexo masculino é predominante e o Estado com a maior presença masculina foi a Paraíba.

Os agricultores familiares constituem 85,98\% dos beneficiários do Programa. $\mathrm{O}$ Estado de Pernambuco possui o maior número de beneficiários agricultores familiares. Minas Gerais é o único Estado que possui beneficiários em todas as categorias analisadas.

O orçamento do PAA é composto por recursos do Ministério do Desenvolvimento Social (MDS) e do Ministério do Desenvolvimento Agrário (MDA). O Estado de Alagoas foi o que mais recebeu recursos, seguido de Minas Gerais. O Estado de Sergipe é o que possui os recursos mais baixos.

A análise de agrupamento permitiu que os dados disponíveis dos beneficiários do PAA-Leite fossem agrupados em 5 clusters. Foi possível classificar em grupos homogêneos a totalidade dos beneficiários, separados em cinco grupos, nos quais os grupos $4(33,5 \%)$ e $2(26,5 \%)$ possuem a maior quantidade de beneficiários, enquanto que o grupo $5(10,5 \%)$ ficou com a menor quantidade.

Ao analisar os clusters separadamente nota-se que os perfis dos beneficiários modificam um pouco entre os grupos. $\mathrm{Na}$ distribuição dos grupos segundo o gênero, $80,11 \%$ do total é composto pelo sexo masculino, apesar da prioridade dada as mulheres nos principais programas sociais do Governo Federal.

De acordo com os recursos disponibilizados pelo Governo Federal para o Programa de Aquisição de Alimentos (PAA-Leite), não houve grandes disparidades entre os clusters formados, os valores médios estão todos acima do valor de R\$ $5.000 .000,00$. 
Com base nas categorias dos beneficiários pelo programa a maioria são compostos de agricultores familiares. Quando se trata da distribuição dos clusters com base no grupo PRONAF, os grupos 1 e 3 são os mais heterogêneos, possuindo todas as categorias estudadas. Em ambos os grupos o tipo de PRONAF predominante foram o B e o V

Os estados com menores participações nos clusters são o Ceará, que está presente somente no cluster 1 e a Paraíba no cluster 5. Conclui-se que os municípios de Pernambuco, Ceará, Minas Gerais e Paraíba são os que mais apareceram na formação dos clusters.

Através da inferência estatística da significância das variáveis em cada grupo, chegou-se a conclusão de que todas as variáveis qualitativas analisadas (município, categoria, sexo e grupo PRONAF) foram significantes estatisticamente. Em geral, as variáveis mais significantes foram Município e Grupo PRONAF. 


\section{REFERÊNCIAS}

BANCO DO NORDESTE DO BRASIL. Importância da Agricultura Familiar, 2012. Disponível em: http://www.bnb.gov.br/agricultura-familiar. Acesso em: 12 de Jan. 2016.

DEPARTAMENTO DE ESTUDOS SÓCIO-ECONÔMICOS RURAIS. O Programa de Aquisição de Alimentos e sua relação com a Política Nacional de Segurança Alimentar e Nutricional e a Política de Comercialização Agrícola no Brasil, entre 2003-07: uma Avaliação. Curitiba: DESER, 2008.

INSTITUTO BRASILEIRO DE GEOGRAFIA E ESTATISTICA. Censo Agropecuário de 2006. Rio de Janeiro: IBGE, 2006. Disponível em: http://www.ibge.gov.br. Acesso em: 03 de Dez. 2015.

INSTITUTO BRASILEIRO DE GEOGRAFIA E ESTATISTICA. Pesquisa Pecuária Municipal, Produção Leiteira, 2014. Rio de Janeiro: IBGE, 2014. Disponível em: http://www.ibge.gov.br. Acesso em: 20 de Fev. 2016.

MELO, Lígia Albuquerque de. Injustiças de Gênero: o trabalho da mulher na agricultura familiar. In: ENCONTRO DA ASSOCIAÇÃO BRASILEIRA DE ESTUDOS POPULACIONAIS, 13,2002, Ouro Preto. Anais... Ouro Preto: Associação Brasileira de Estudos Populacionais, 2002, 14p.

OLIVEIRA, Lucia Andrea Sindeaux et al. Políticas Públicas e Estratégia Sustentável de Combate à Fome: o caso do PAA-Leite no Município de Quixeramobim-Ceará. Revista de Economia e Agronegócio-REA, v. 10, n. 2, p. 285-306. 2015.

PAULILO, Maria Ignez Silveira, DE GRANDI, Alessandra Bueno; SILVA, Marineide Maria. Mulher e atividade leiteira: a dupla face da exclusão. In: PAULILO, Maria Ignez Silveira; SCHMIDT, Wilson (Org.) Agricultura e espaço rural em Santa Catarina. Florianópolis: Editora da UFSC, 2003.

PORTAL BRASIL. Entenda o Programa de Fortalecimento da Agricultura Familiar - PRONAF, 2015. Disponível em: http://www.brasil.gov.br/economia-eemprego/2015/08/entenda-o-programa-de-fortalecimento-da-agricultura-familiarPRONAF. Acesso em: 01 de Fev. 2016.

SCHIOPU, D. Applying TwoStep Cluster Analysis for Identifying Bank Customers Profile. Petroleum-Gas University of Ploiesti Bulletim, Economic Sciences Series, v.62, n.3, p.66-76, 2010.

SCHMITT, Claudia Job. Aquisição de Alimentos da Agricultura Familiar: integração entre política agrícola e segurança alimentar e nutricional. Revista de Política Agrícola, v.14, n.2, p.78-88, 2005.

SERVIÇO BRASILEIRO DE APOIO AS MICRO E PEQUENAS EMPRESAS. Produção de Leite na Região Nordeste. [s.1.]: SEBRAE, 2014. Disponível em: http://www.sebrae.com.br. Acesso em: 06 de Jan. 2016. 
VIEIRA, Deborah de F.A.; VIANA, Carla A. dos S. O Programa de Aquisição de Alimentos-PAA e sua relação com o modo de funcionamento da Agricultura Familiar. IN: CONGRESSO BRASILEIRO DE SISTEMAS DE PRODUÇÃO, 7, 2007, Fortaleza. Anais... Fortaleza: Embrapa Agroindústria Tropical, 2007. v.1.

YASBEK, Maria Carmelita. O Programa Fome Zero no Contexto das Políticas Sociais Brasileiras. São Paulo em Perspectiva, 18(2): 104-112, 2004. Disponível em http://www.scielo.br/scielo.php?script=sci_arttext\&pid=S0102-88392004000200011. Acesso em: 21 de Out. 2016. 